have to be calculated for certain suitable and equidistant intervals of time. Knowing the hourly movements of the moon in right ascension and polar distance for the same instants from the almanack, and the elements of the phenomena, whether it be eclipse or occultation, the tracing of the positions of the bodies may be proceeded with. The plane of the drawing is supposed to represent that plane which is at right angles to the line joining the centre of the moon and the observer, at any one of the chosen instants near the time of conjunction of the two bodies. On this plane the successive projected true and apparent positions of the two bodies, sun and moon, or moon and star, are considered. The line passing through the centres of the moon in her different positions will thus represent the apparent lunar orbit, and if in addition we know the position at the moment of true conjunction of the two bodies, occupied by the centre of the sun or star, according as we are dealing with an eclipse or occultation, it will be easy to find the positions of the centres at the moments of contact, or of immersion and emersion, and also the times.

The calculation of the elements necessary for making the drawing would have for its aim the determination of the co. ordinates of the points of the apparent orbit occupied by the centre of the moon. This work is here rendered very easy by using the series of tables which have been prepared for reducing the calculation to a minimum. As an illustration showing the method of procedure, Mr. Cruls gives two complete worked-out cases, one of the eclipse of the sun at Rio de Janeiro April 16, 1893, and another of the occultation of a Virginis on March 22, I894, at Greenwich. The accuracy of this graphical method may be gauged from the observed minus calculated values obtained in the two cases just mentioned.

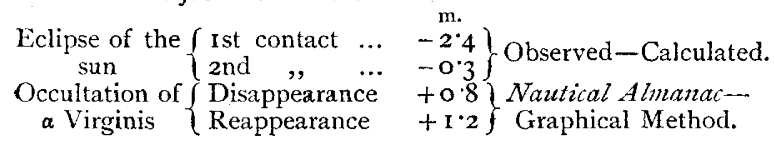

PENDULUM OBSERVATIONS IN GERMANY.

I $\mathrm{T}$ is a well-known fact that, at different places on the earth's surface and at the same sea-level, pendulums change their rates of swing. The numerous observations of von Sterneck, made in the region of the Alps, suggested that such deviations from the normal might be, and were most probably, explained on the supposition of unequal distributions of the masses in the neighbourhood-that is, either inside the mountains or in the earth's crust itself. Such observations as these indicated that good work might be done in this direction, and in consequence measurements were made on Mont Blanc, while in other directions observations were being organised by the scientific societies in Vienna, München, Leipzig, and Cö̈ttingen. The gravity determinations on Mount Blanc were made at the new observatory, and M. Jannsen informs us that besides those made in Chamounix in the previous summer, and on the Grands Mulets (3050 metres elevation), by M. Bigourdan, an effort will be made to continue them this summer on the summit itself. The results which have been obtained up to the present are as yet unpublished. A region which appeared full of interest for investigating the different rates of swinging pendulums is that in the region of Göttingen and the Harz Mountains. Prof. von Könen singled out what he thought were the three most suitable spots on account of their different geological conditions for such investigations, and observations at these stations were all compared with those made at Göttingen, this being the chief observing station on account of the observatory. It is true that the instrument employed in these determinations was far too rough for accurate and reliable measurements, it being the one which Dr. von Drygalski had previously used on his Greenland expedition, and with which Sterneck made his first experiments. The actual observations were made by Prof. Wilhelm Schur and Dr. Grossmann, and the results were communicated to the Nachrichten der K. G. der Wiss. Gött., Heft 2, 1895. These may be summed up as follows. In the cases of the two stations at Griinenplan and Teichmühle, the very small differences when compared with Göttingen may be neglected when the kind of instrument employed be taken into consideration. The difference for the station Sack, on the other hand, was comparatively large, the numbers being-
For Grünenplan
Sack
- 0:00018
$-0.0008 \mathrm{r}$
Teichmühle
$-0.00028$

The conclusion drawn by Prof. ron Könen from this somewhat rough determination was that the diminution in the intensity of gravity for the station Sack might possibly be due to the present condition of the positions of the underlying superposed strata (Schichteniiberschiebung).

Since the above determinations were made, the same ground has been covered, in September and October last, by Herr Haasemann, who, at the request of Geheimrath Helmert, undertook to make a series of measurements at the same observing stations as used by Prof. Schur. In this new investigation the instruments employed were more accurate and of later design, so that the results may be looked upon as more trustworthy and accurate. Limiting ourselves to giving the actual numerical results, the differences for the three stations when compared as before with Göttingen were--
For Grünenplan
Sack
Teichmühle
$+0.00007$
- 0.00003
- O.OOOI I

Comparing these figures with those obtained by Prof. Schur, the large difference for Sack entirely disappears. This indicates that at these places the determinations of the rates of the pendulums give no trace of any variation in the intensity of gravity, or at least of any variation which is capable of being detected by the apparatus employed.

D.

\section{PETROLEUM LAMP ACCIDENTS.}

THE report of Mr. Alfred Spencer, chief officer of the Public Control Department of the London County Council, as to the causes of petroleum lamp accidents, and as to the measures necessary for preventing them, which has just been issued, is an important document. The number of accidents due to the use of cheap and unsafe petroleum lamps has assumed alarming proportions within the past few years, that the means by which the accidents can be prevented cannot be too prominently or too frequently brought before the public. Mr. Spencer has made a thorough investigation with numerous lamps and stoves in which petroleum is used, in order to determine the conditions of safety. The results of his experiments lead him to conclude that raising the flash-point fixed by the Petroleum Acts would not alone be effectual in preventing lamp accidents, as this would not prevent the sale and use for illuminating purposes of oil below that flash-point. He remarks, however, that the prohibition of the retail sale, and the prevention of the use for illuminating purposes of mineral oil below a flashing-point sufficiently high to prevent all lamp accidents, would be effectual if it were practicable. The prohibition by statute of the sale of unsafe lamps would be another means of putting an end to lamp accidents, as both experience and experiment have proved that mineral oils, such as are now in common use, can be safely burnt in properly constructed lamps. The difficulties in the way of prohibiting the sale of unsafe oil are far greater than would be met in regulating the construction and sale of safe lamps; therefore Mr. Spencer suggests that the latter is the means of safety which should be enforced by order of the Secretary of State. His suggestions for the safe construction and proper management of lamps, revised in the light of recent experiments, are as follows :-

\section{CONSTRUCTION.}

(I) The oil reservoir should be of strong metal, properly folded and soldered at the joint, and should not be of china, glass, or other fragile material.

(2) There should be no opening between the reservoir and the burner, other than through the tube which holds the wick; and this tube should be extended to within $\frac{1}{4}$ in. of the bottom of the reservoir, and should have no opening into the reservoir except at its base.

(3) The burner should be securely attached to the reservoir, preferably by means of a strong and well-made screw attachment.

(4) There should be no openings through which oil could flow from the reservoir should the lamp be upset.

(5) Every table lamp should have a broad and heavy base, to which the reservoir should be strongly attached.

\section{Wicks.}

(6) Wicks should be soft, and not tightly plaited, and should quite fill the wick-tube without having to be squeezed into it.

(7) Wicks should be frequently renewed, and before being put into lamps should be dried at a fire and then immediately soaked with oil. 